\title{
Effect of Intensive Phototherapy on Bilirubin Induced Neurological Defect (BIND) Score in Neonates with Severe Hyperbilirubinemia
}

Yasser Abdelrahman Ahmed, Yasser Tolba Kassem, Samar Abdel Nafae Ismail

Pediatrics and Neonatology Department, Faculty of Medicine, Al-Azhar University, Assuit

Corresponding author: Samar Abdel Nafae Ismail, Mobile: (+20)01000962976, Email: dr7oodasamar@ gmail.com

\begin{abstract}
Background: neonatal hyperbilirubinemia is a leading cause of morbidity and mortality in developing countries. Adverse consequences include neonatal mortality, classic manifestations of choreoathetoid cerebral palsy, isolated auditory impairment, and a diverse manifestation of subtle processing disorders because of BIND.

Aim of the Work: the aim of the current study was to evaluate the effectiveness of intensive phototherapy on BIND score in neonates with severe hyperbilirubinemia. Patients and Methods: the current study is a prospective study conducted on 100 neonates with severe hyperbilirubinemia admitted to NICU at university Hospital, Faculty of Medicine, Al-Azhar University, Assuit, Egypt in the period between November 2017 and May 2018. The study group was divided into 2 groups, hemolytic and non-hemolytic hyperbilirubinemia groups.

Results: regarding TSB and direct bilirubin at admission no significant difference was detected between both groups ( $\mathrm{p}=0.543$ and 0.632 ). Regarding TSB and direct bilirubin at discharge no significant difference was detected between both groups ( $\mathrm{p}=0.712$ and 0.213 ). Results show no significant change between hemolytic and nonhemolytic jaundice regarding rate of decline per hour of total bilirubin and direct bilirubin after 8 hs. No significant difference between study groups regarding BIND score at admission. At discharge, 95 (95\%) neonates had BIND score 0 and 4 (4\%) had BIND score 1-3. One neonate (1\%) died before scoring.

Conclusion: care must be taken not to delay the decision of exchange transfusion to the degree that endangers baby's life. BIND score can be used to assess the efficacy of intensive phototherapy in newborn with hyperbilirubinemia.
\end{abstract}

Keywords: Intensive Phototherapy, Bilirubin, Neurological Defect, Neonates, Severe Hyperbilirubinemia.

\section{INTRODUCTION}

Neonatal jaundice is defined as yellow discoloration of the skin, sclera from the eyeball, and mucous membranes caused by bilirubin deposition in these tissues. Jaundice may be present at birth or at any time during the neonatal period. Jaundice should be taken seriously because of indirect (non-associated) or direct bilirubin (conjugated) during the first 24 hours of life ${ }^{(\mathbf{1})}$.

In a recent study performed in the NICU of Azhar Assuit, University hospital in year 2018, cases of neonatal hyperbilirubinemia represented $45.3 \%$ of total admission, with total serum bilirubin level ranging from $8.6-58.5 \mathrm{mg} / \mathrm{dL}$, where total serum bilirubin between $20-25 \mathrm{mg} / \mathrm{dL}$ was $26.5 \%$, total serum bilirubin between 25-30 $\mathrm{mg} / \mathrm{dL}$ was $20.8 \%$ and above $30 \mathrm{mg} / \mathrm{dL}$ was $19.1 \%$. So hyperbilirubinemia remains a serious problem in our country that needs further studying (2). Bilirubin toxicity remains a significant problem despite recent advances in the care of jaundiced (hyperbilirubinemic) neonates. There is a recent increase in reported cases of classical kernicterus, partly due to earlier hospital discharge and relaxation of treatment criteria for hyperbilirubinemia ${ }^{(3)}$.

Acute kernicterus remains a clinical emergency. Clinical "Bilirubin induced neurological dysfunction" BIND is the score of onset, severity and progression of acute bilirubin encephalopathy in infants with hyperbilirubinemia (total serum bilirubin $>95$ th percentile for age in hours) as elicited by history and physical examination ${ }^{(4)}$. Intensive phototherapy in neonatal hyperbilirubinemia rapidly decreases total serum bilirubin (TSB) below the threshold for treatment (5). Bilisphere is a novel neonatal phototherapy device designed to provide blue light illumination to the whole of a baby's skin surface. Neonatal phototherapy is most effective at high irradiance and high treatment area coverage; the bilisphere 360 is designed to maximise both factors. This standalone device is mounted on a mobile stand with four wheels each with a brake. The therapy chamber is a horizontal cylinder containing 16 blue TL 20W/52 fluorescent tubes ${ }^{(6)}$.

\section{AIM OF THE WORK}

The aim of the current study is to evaluate of the effectiveness of intensive phototherapy on bilirubin induced neurological dysfunction (BIND) score in neonates with severe hyperbilirubinemia.

\section{PATIENTS AND METHODS}

This study was conducted as a prospective study on 100 neonates with severe hyperbilirubinemia admitted to NICU at University Hospital, Faculty of Medicine, Al-Azhar University, Assuit, Egypt, in the period between November 2017 and May 2018. The study was approved by the Ethics Board of Al-Azhar University.

The study group was divided into 2 groups, hemolytic and non-hemolytic. 


\section{Inclusion criteria}

Any baby admitted with severe jaundice fulfilling the following data:

1. Gestational age $(\mathrm{GA}) \geq 36 \mathrm{wks}$

2. Hemolytic and nonhemolytic jaundice

3. $\mathrm{TSB} \geq 20 \mathrm{mg} / \mathrm{dL}$

4. No major birth defects

Hemolytic cases are characterized by increased unconjugated bilirubin level, high reticulocytic count more than 6 , hemoglobin concentration less than $13 \mathrm{~g} / \mathrm{dl}$ and positive Coombs test in $\mathrm{ABO}, \mathrm{Rh}$ and minor group incompatibility.

\section{Exclusion criteria:}

- Life threatening conditions:

- Congenital malformation

- Acquired life threatening conditions e.g.; shock, respiratory failure and post arrest.

Written Informed consents were obtained from parents or care givers then all the neonates included in the study were subjected to the following:

\section{A) Detailed History taking including Maternal history:}

- Blood group, family history of neonatal jaundice family history of G6PD.

\section{Perinatal history:}

- Antenatal: gestational age.

- Natal: mode of delivery.

- Postnatal: age, sex and weight on admission

\section{B) Examination:}

Neurological examination was performed during the stay in our hospital every 8 hours.

Assessment of BIND score depends on the mental status, muscle tone and cry pattern of the neonates and was done before and after intensive phototherapy.

1. Mental status data e.g.; normal, sleepy but arousable, decreased feeding, lethargy, poor sucking, irritable, jittery with strong sucking, semi-coma, apnea, unable to feed, seizures, coma.
2. Muscle tone data e.g.; normal, persistent mild to moderate hypotonia, mild to moderate hypertonia alternating with hypotonia, beginning arching of neck and trunk on stimulation, persistent retrocollis and opisthotonos, bicycling or twitching of hands and feet.

3. $\quad$ Cry pattern data e.g.; normal, high pitched when aroused, shrill, difficult to console, inconsolable crying or cry weak or absent.

\section{C) Laboratory investigation:}

Serum total bilirubin and direct bilirubin on admission and repeated after 8 hours.

Hemoglobin, reticulocytic count, Coombs test, blood group of the infant.

\section{D) Interventions:}

The patients were put into intensive phototherapy (Novos-360). Bilisphere provides intensive, multi-directional phototherapy treatment to newborn jaundice and brings new standards and benefits for newborns.

\section{Primary outcome parameters}

The degree of decrements of BIND scores in response to intensive phototherapy.

\section{Secondary outcome parameters}

The rate of decline in using exchange transfusion in neonates with severe hyperbilirubinemia in relation to previous years before getting intensive phototherapy.

\section{Statistical analysis}

Data were statistically analyzed using standard computer program (SPSS) software package. The following tests were used: Frequency distributions, percentage distributions, Means \pm standard deviation, and tests of correlation. Confidence intervals $(95 \%$ CI) were calculated when appropriate. Significance was adopted at $\mathrm{P}<0.05$ for interpretation of results of tests of significance. $\quad \mathrm{P}<0.01$ was considered highly significant, while $\mathrm{P}>0.05$ was considered nonsignificant.

\section{RESULTS}

Table (1): Demographic data of the study groups.

\begin{tabular}{|c|c|c|c|c|c|}
\hline & Non & $(\mathbf{n}=\mathbf{5 0})$ & $\mathrm{He}$ & $1=50)$ & \\
\hline & & & & & p-value \\
\hline GA (weeks) & & & & & $>0.05$ \\
\hline Age on admission (days) & & & & & $<0.001 *$ \\
\hline Weight on admission (gm) & & & & & $>0.05$ \\
\hline Sex & (n) & $(\%)$ & (n) & $(\%)$ & \\
\hline Male & 40 & $80 \%$ & 35 & $70 \%$ & $>0.05$ \\
\hline Female & 10 & $20 \%$ & 15 & $30 \%$ & \\
\hline Consanguinity & & & & & \\
\hline Negative & 46 & $92 \%$ & 46 & $92 \%$ & $>0.05$ \\
\hline Positive & 4 & $8 \%$ & 4 & $4 \%$ & \\
\hline Family history of G6PD & & & & & \\
\hline Negative & 45 & $90 \%$ & 40 & $80 \%$ & $>0.05$ \\
\hline Positive & 5 & $10 \%$ & 10 & $20 \%$ & \\
\hline
\end{tabular}

* Significance at $<0.05$ 
As regard the demographic data of the neonates a significant higher age on admission in non-hemolytic group $(6.11 \pm 2.55)$ than hemolytic group $(4.14 \pm 2.23)$, ( $<<0.001)$ was detected. On the other hand both groups were comparable regarding GA, weight on admission, days of hospitalization, gender, consanguinity and family history of G6PD (Table 1).

Table (2): Mode of delivery of the study groups.

\begin{tabular}{|l|c|r|r|r|c|}
\hline & \multicolumn{2}{|c|}{ Non-hemolytic (n=50) } & \multicolumn{2}{|c|}{ Hemolytic (n=50) } & p-value \\
\hline Mode of delivery & $(\mathrm{n})$ & $(\%)$ & $(\mathrm{n})$ & $(\%)$ & $>0.05$ \\
VD & 35 & $70 \%$ & 30 & $60 \%$ & \\
CS & 15 & $30 \%$ & 20 & $40 \%$ & \\
\hline
\end{tabular}

No significant difference between study groups regarding mode of delivery.

Table (3): Gestational age (GA) groups in the study groups.

\begin{tabular}{|l|c|c|c|c|c|}
\hline & \multicolumn{2}{|c|}{ Non-hemolytic (n=50) } & \multicolumn{2}{|c|}{ Hemolytic (n=50) } & p-value \\
\hline GA groups & $(\mathrm{n})$ & $(\%)$ & $(\mathrm{n})$ & $(\%)$ & \\
36-38 wks & 14 & $28 \%$ & 13 & $26 \%$ & $>0.05$ \\
$>\mathbf{3 8}$ wks & 36 & $72 \%$ & 37 & $74 \%$ & \\
\hline
\end{tabular}

No significant difference between study groups regarding gestational age.

Table (4): Comparison between study groups regarding laboratory data at admission.

\begin{tabular}{|l|c|c|c|}
\hline & Non-hemolytic (n=50) & Hemolytic (n=50) & \multirow{2}{*}{ p-value } \\
\cline { 2 - 3 } & Mean+SD & Mean \pm SD & $>0.05$ \\
\hline TSB (mg/dl) & $26.01 \pm 4.85$ & $27.1 \pm 5.0$ & $>0.05$ \\
\hline $\begin{array}{l}\text { Direct bilirubin } \\
\text { (mg/dl) }\end{array}$ & $0.93 \pm 0.09$ & $1.10 \pm 0.17$ & $<0.001^{*}$ \\
\hline HB $(\mathbf{g m} / \mathbf{d l})$ & $15.32 \pm 1.87$ & $11.4 \pm 2.5$ & $<0.001^{*}$ \\
\hline Retics & $3.19 \pm 0.99$ & $10.22 \pm 2.04$ & $<0.001^{*}$ \\
\hline HCT & $46.0 \pm 5.87$ & $33.2 \pm 7.2$ & \\
\hline
\end{tabular}

$*$ Significance at $<0.05$

Table (4) shows highly significant increase of hemoglobin in non-hemolytic than hemolytic jaundice, highly significant decrease of reticulocytic count in non-hemolytic than hemolytic and highly significant higher HCT in non-hemolytic than hemolytic. Regarding TSB and direct bilirubin at admission no significant difference was detected between both groups.

Table (5): Comparison between study groups regarding laboratory data after 8 hours.

\begin{tabular}{|l|c|c|c|}
\hline & Non-hemolytic $(\mathbf{n}=\mathbf{5 0})$ & Hemolytic $(\mathbf{n}=\mathbf{5 0})$ & \multirow{2}{*}{ p-value } \\
\cline { 2 - 3 } & Mean+SD & Mean \pm SD & $>0.05$ \\
\hline TSB (mg/dl) & $18.21 \pm 3.46$ & $18.4 \pm 3.4$ & $>0.05$ \\
\hline $\begin{array}{l}\text { Direct bilirubin } \\
(\mathrm{mg} / \mathrm{dl})\end{array}$ & $0.87 \pm 0.04$ & $0.79 \pm 0.08$ & \\
\hline
\end{tabular}

Regarding TSB and direct bilirubin after 8 hours under Bilisphere no significant difference was detected between both groups (Table 5).

Table (6): The rate of decline per hour in different study groups after intensive phototherapy.

\begin{tabular}{|l|c|c|c|c|c|}
\hline \multirow{2}{*}{ Group } & \multicolumn{2}{|c|}{ Non-hemolytic Group } & \multicolumn{2}{|c|}{ Hemolytic Group } & \multirow{2}{*}{ P } \\
\cline { 2 - 5 } & \multicolumn{2}{|c|}{ \% Change } & \multicolumn{2}{|c|}{ \% Change } & \\
\cline { 2 - 5 } & Mean \pm SD & Mean \pm SD & Mean \pm SD & Mean \pm SD & \\
\hline TSB on admission & $26.9 \pm 5.3$ & & $27.1 \pm 5.0$ & & \multirow{2}{*}{$>0.05$} \\
\hline TSB after 8h & $18.21 \pm 3.6$ & $1.28 \pm 0.03$ & $18.4 \pm 3.4$ & $1.58 \pm 1.26$ & \\
\hline $\begin{array}{l}\text { Direct bilirubin on } \\
\text { admission }\end{array}$ & $0.96 \pm 0.09$ & & $1.10 \pm 0.17$ & & \multirow{2}{*}{$>0.05$} \\
\hline Direct bilirubin after 8 hs & $0.87 \pm 0.04$ & $0.02 \pm 0.003$ & $0.79 \pm 0.08$ & $0.05 \pm 0.15$ & \\
\hline
\end{tabular}

Table 6 shows no significant change between hemolytic and nonhemolytic jaundice regarding rate of decline per hour of total bilirubin and direct bilirubin after 8hs. 
Table (7): Comparison between studies groups regarding BIND score at admission.

\begin{tabular}{|c|c|c|c|}
\hline & Non-hemolytic $(\mathbf{n}=\mathbf{5 0})$ & Hemolytic $(\mathbf{n}=\mathbf{5 0})$ & p-value \\
\hline BIND & Range 0-6 & Range 0-4 & $>0.05$ \\
score & Median 0 & Median 0 & \\
\hline
\end{tabular}

No significant difference between study groups regarding BIND score at admission.

Table (8): Comparison between study groups regarding BIND score at discharge.

\begin{tabular}{|c|c|c|c|}
\hline & Non-hemolytic (n=50) & Hemolytic (50) & p-value \\
\hline BIND & Range 0-3 & Range 0-2 & $>0.05$ \\
score & Median 0 & Median 0 & $>0.05$ \\
\hline
\end{tabular}

At discharge, 95 (95\%) neonates had BIND score 0 and 4 (4\%) had BIND score 1-3. One neonate (1\%) died before scoring.

Table (9): Comparison between BIND score at admission and after 8 hours.

\begin{tabular}{|l|c|c|c|}
\hline & $\begin{array}{c}\text { BIND score at } \\
\text { admission }\end{array}$ & $\begin{array}{c}\text { BIND score after 8 } \\
\text { hours }\end{array}$ & P \\
\hline Normal $(0)$ & $70(70 \%)$ & $94(94 \%)$ & 0.001 \\
Abnormal $(1-6)$ & $30(30 \%)$ & $6(6 \%)$ & 0.001 \\
\hline
\end{tabular}

* Significance at $<0.05$

At the time of admission, 30 infants $(30.0 \%)$ had a BIND score of 1-6 indicating subtle, moderate or severe acute bilirubin encephalopathy (ABE) while $70(70 \%)$ babies had no evidence of ABE. Most babies improved with treatment apart from $6(6 \%)$ patients who had persistent evidence of bilirubin encephalopathy after 8 hours. This difference was highly statistically significant.

Table (10): Exchange transfusion according to type of jaundice.

\begin{tabular}{|l|c|c|c|c|c|}
\hline & \multicolumn{2}{|c|}{ Non-hemolytic (n=50) } & \multicolumn{2}{|c|}{ Hemolytic (n=50) } & p-value \\
\hline Exchange & $(\mathrm{n})$ & $(\%)$ & $(\mathrm{n})$ & $(\%)$ & $>0.05$ \\
Yes & 3 & $6 \%$ & 2 & $4.0 \%$ & \\
No & 47 & $94 \%$ & 48 & $96 \%$ & \\
\hline
\end{tabular}

Exchange transfusion required in 3 neonates $(6 \%)$ in non-hemolytic group and 2 neonates $(4.0 \%)$ of the hemolytic group.

Table (11): Days of hospitalization of the study groups.

\begin{tabular}{|c|c|c|c|}
\hline & Non-hemolytic $(\mathbf{n = 5 0})$ & Hemolytic $(\mathbf{n}=\mathbf{5 0})$ & \multirow{2}{*}{$\begin{array}{c}\mathbf{p}- \\
\text { value }\end{array}$} \\
\cline { 2 - 3 } & Mean \pm SD & Mean \pm SD & $>0.05$ \\
\hline Days of hospitalization & $3.34 \pm 0.06$ & $3.82 \pm 0.81$ & $>$ \\
\hline
\end{tabular}

No significance difference between study groups regarding days of hospitalization.

\section{DISCUSSION}

Neonatal hyperbilirubinemia continues to be a leading cause of morbidity and mortality in resourcelimited countries ${ }^{(7)}$.

More than $80 \%$ of preterm and postnatal preterm infants suffer from nonverbal hyperbilirubinemia, which appears in the form of jaundice during the first week after birth. When postpartum children are monitored at the postpartum age, at-risk children sometimes need early and effective follow-up and possible interventions for the bilirubin vacuum. If unrecognized, the safety margin is narrow, and healthy newborns can be damaged by untreated brain damage ${ }^{(\mathbf{8})}$.

Adverse consequences include neonatal mortality, classic manifestations of brachial cerebral palsy, isolated auditory impairment, and various manifestations of hidden treatment disorders due to biliary dysfunction caused by bilirubin (BIND) ${ }^{(9)}$.
The exact threshold in which bilirubin may be neurotoxic in a given infant is unknown and controversial. Better understanding and the ability to measure the association of bilirubin-albumin may help resolve this uncertainty ${ }^{(\mathbf{1 0})}$.

Phototherapy has been accepted as a standard treatment for neonatal jaundice, and there are different ways to offer phototherapy. The efficiency of phototherapy depends on emissions, peak wave length of the light source, radiation, and surface area of the exposed body, regardless of the different clinical factors ${ }^{(11)}$.

In severe and rapidly increasing jaundice, the use of high-intensity phototherapy provides greater effectiveness and a faster decrement in bilirubin levels. Multiple phototherapy units are used to increase the light intensity and thus improve the efficiency of phototherapy ${ }^{(12)}$. 
Yasser Ahmed et al.

Results of our study show highly significant higher hemoglobin in non-hemolytic than hemolytic, highly significant lower reticulocytic count in nonhemolytic than hemolytic and highly significant higher HCT in non-hemolytic than hemolytic. Regarding TSB and direct bilirubin at admission no significant difference was detected between both groups.

A significant higher age on admission in nonhemolytic group than hemolytic group, was detected. On the other hand both groups were comparable regarding GA, weight on admission, days of hospitalization, gender, consanguinity and family history of G6PD.

Similar to our results, Bhutani et al. ${ }^{(11)}$ found significant higher age of onset of nonhemolytic (6.11 \pm 2.55 days) compared to hemolytic jaundice (4.14 \pm 2.23 days). They also found no significant difference between both groups regarding weight, gender or consanguinity. Kaplan et al. ${ }^{(13)}$ reported that G-6-PD deficiency is associated with neonatal hyperbilirubinemia. Its potentially devastating complication of kernicterus was reported. Unlike our results they found higher prevalence of G6PD history in neonates with hemolytic jaundice. This can be explained by the different ethnicity in our sample from their sample.

Results of the current study show that $34 \%$ of neonates had Coombs' positive test while $66 \%$ had Coombs' negative test. Among study group, 56\% neonates had non-hemolytic jaundice, and 44 neonates had hemolytic jaundice of them, $27 \%$ neonates had ABO incompatibility, $6 \%$ had RH incompatibility, $7 \%$ had undefined cause and $4 \%$ had ABORH incompatibility.

Similar to our results, Brits et al. ${ }^{(8)}$ found that common risk factors for hyperbilirubinemia include fetal-maternal blood group incompatibility (25.6\%), RH incompatibility (8.5\%) and ABORH incompatibility (2.9\%). Gamaleldin et al. ${ }^{(14)}$ found that $\mathrm{ABO}$ incompatibility is responsible for $23.7 \%$ and RH incompatibility for $8.8 \%$ of cause of neonatal admission with jaundice to NICU.

On the other hand Akguil et al. ${ }^{(15)}$ found that $\mathrm{ABO}$ incompatibility is responsible for $75 \%$ of causes of neonatal admission with jaundice to NICU, and this percent was higher than our results (27\%).

Results of the current study showed that the rate of decline of TSB in nonhemolytic group was $1.28 \pm 0.83 \mathrm{mg} / \mathrm{dl} / \mathrm{hr}$ and in hemolytic group was $1.58 \pm 1.26 \mathrm{mg} / \mathrm{dl} / \mathrm{hr}$. The rate of decline of direct bilirubin in nonhemolytic group was $0.02 \pm 0.13$ $\mathrm{mg} / \mathrm{dl} / \mathrm{hr}$ and in hemolytic group was $0.05 \pm 0.15$ $\mathrm{mg} / \mathrm{dl} / \mathrm{hr}$. No significant change between hemolytic and nonhemolytic jaundice regarding rate of decline per hour of total bilirubin and direct bilirubin after 8hs.

Similar to our results, Umran (16), demonstrated the efficacy of intensive phototherapy and reported that the reduction rate of total serum bilirubin in nonhemolytic hyperbilirubinemia was 1.3 $\mathrm{mg} / \mathrm{dl} / \mathrm{hr}$. also Abd-Ellatif and Abd-Ellatif ${ }^{(17)}$ found that the mean rate of TSB declined during stay in the bilisphere was $1.019 \mathrm{mg} / \mathrm{dl} / \mathrm{hr}$.

On the other hand De Carvalho et al. ${ }^{(18)}$, found that the rate of decline of TSB in nonhemolytic jaundice was $0.8 \mathrm{mg} / \mathrm{dl} / \mathrm{hr}$ after 6 hours, and this rate was slower than our rate. This can be explained by the fact that they used a different type of light source as they used blue fluorescent light.

Also Al-Hafidh et al. ${ }^{\left({ }^{19)}\right.}$ found a lower rate of decline $(0.81 \pm 0.38 \mathrm{mg} / \mathrm{dl} / \mathrm{hr})$ although they used bilisphere similar to our study, the difference can be explained as they measured their rate after 6 hours and the initial TSB was lower in their population (18.85 \pm $4.57 \mathrm{mg} / \mathrm{dl}$ ).

Bilirubin induced neurological dysfunction (BIND) score was performed to all neonates in our study at admission and on discharge from NICU. No significant difference between study groups regarding BIND score at admission $(\mathrm{p}=0.632)$ and at discharge $(\mathrm{p}=0.851)$.

Neonates with BIND scores 4-6 represent cases with moderate acute bilirubin encephalopathy and are likely to be reversible with urgent bilirubin reduction ${ }^{(4)}$.

Similar to our results Gamaleldin et al. (14) found that most of their neonates with neonatal hyperbilirubinemia had BIND score 0 (normal) on admission (60\%), BIND score 1-6 in 32\% neonates and only $8 \%$ had BIND score more than 6 (sever affection). On discharge, no infants with normal BIND on admission developed later signs of bilirubin encephalopathy (BE). Neonates with moderate BIND score (of 4-6) and with severe BIND score (of 7-9) had persistent evidence of $\mathrm{BE}$ at the time of death or discharge.

Johnson and Bhutani ${ }^{(20)}$ believe that BIND represents a spectrum of neurologic manifestations among vulnerable infants who have experienced an exposure to bilirubin.

In the current study all neonates had intensive phototherapy and only 5\% of them needed single exchange transfusion. Exchange transfusion required in 3 neonates $(6 \%)$ in non-hemolytic group and 2 neonates $(4.0 \%)$ of the hemolytic group.

Similar to our results, Bradley et al. (21) measured the efficacy of phototherapy in reduction of exchange transfusions in NICU. They found that only $3 \%$ of their cases required exchange transfusion.

Also, Abd-Ellatif and Abd-Ellatif ${ }^{(17)}$ found that exchange blood transfusion was performed in 13 cases out of 212 with extreme hyperbilirubinemia.

On the other hand De Carvalho et al. ${ }^{(18)}$, reported $100 \%$ rate in avoiding exchange transfusion after the use of intensive phototherapy with no cases required exchange transfusion. This difference from our results could be explained due to their prolonged 
duration of intensive phototherapy $(35.4 \pm 19.5)$ hours, compared to our duration (8 hours). Also Al-Hafidh et al. (19) found that exchange transfusion was not required in their study after intensive phototherapy. This difference can be explained by their lower initial TSB levels $(18.85 \pm 4.57 \mathrm{mg} / \mathrm{dl})$ compared than our levels.

In conclusion, phototherapy is an important treatment of choice to prevent the complications of unconjugated hyperbilirubinemia. The duration of exposure to elevated total bilirubin level is an important risk factor for acute bilirubin encephalopathy or kernicterus. Effective phototherapy decreasing total bilirubin to safe levels quickly can minimize the risk of bilirubin neurotoxicity ${ }^{(\mathbf{1 2})}$.

\section{CONCLUSION}

From results of the current study we concluded that:

High intensity phototherapy is effective in rapidly decreasing TSB levels and reducing the need for exchange transfusion. Intensive phototherapy can be used for cases with sever hyperbilirubinemia near level of exchange. Care must be taken not to delay the decision of exchange transfusion to the degree that endangers baby's life. BIND score can be used to assess the efficacy of intensive phototherapy in newborn with hyperbilirubinemia.

\section{REFERENCES}

1. Patel AS, Desai DA, Patel AR (2017): Association of $\mathrm{ABO}$ and $\mathrm{Rh}$ incompatibility with neonatal hyperbilirubinaemia. International Journal of Reproduction, Contraception, Obstetrics and Gynecology, 6(4):1368-75.

2. Darlene A, Calhoun L and Weisman E (2017): Jaundice in Neonatology, Pathophysiology and Management of the Newborn. up to date. https://www.uptodate.com/contents/postnatal-diagnosisand-management-of-hemolytic-disease-of-the-fetus-andnewborn

3. Paul D, Berk C, Ewart RC (2018): The role of kinetic analysisand mathematical modeling in the study of bilirubin metabolism in vivo. Bilirubin, 45:133-172.

4. Pichon JBL, Riordan SM and Watchko J (2017): Receptive language and speech production in children with auditory neuropathy/dyssynchrony type hearing loss. Current Pediatric Reviews, 13(3): 199-209.

5. Bansal A, Jain S, Parmar $V$ and Chamla D (2010): Bilirubin rebound after intensive phototherapy for neonatal jaundice. Pediatrics, 47(7): 607-609.

6. Bandyopadhyay A and Maiti R (2017): Acute management extreme neonatal jaundice the potential benefits of intensified phototherapy and interruption of enterohepatic bilirubin circulation. International Journal of Pediatrics, 4(3):853-857.
7. Satrom K, Slusher T and Satrom J (2014): Effectiveness of phototherapy units in Cameroon. Journal of Tropical Pediatrics, 60(3):264-6.

8. Brits H, Adendroff J, Huisamen D (2018): Hyperbilirubinemia in the term newborn. African Journal of Primary Health Care and Family Medicine, 10(1): 1-6.

9. Bhutani VK, Vilms RJ, Hamerman-Johnson L (2010): Universal bilirubin screening for severe neonatal hyperbilirubinemia. J Perinatol., 30:S6-15.

10. Hulzebos CV, PH Dijk, Bos AF et al. (2015): Usefulness of the bilirubin /albumin ratio for predicting bilirubin induced neurotoxicity in premature infants. Plos One, 9(6): e99466.

11. Bhutani VK (2011): Phototherapy to prevent severe neonatal hyperbilirubinemia in the newborn infant 35 or more weeks of gestation. Pediatrics, 128: 1046-1052.

12. Takcı S, Yiğit S, Bayram G, Korkmaz A and Yurdakök M (2013): Comparison of intensive lightemitting diode and intensive compact fluorescent phototherapy in non-hemolytic jaundice. Turk J Pediatr., 55 (1):29-34.

13. Kaplan M, Wong RJ and Stevenson DK (2015): An update on the prevalence of glucose-6-phosphate dehydrogenase deficiency and neonatal jaundice. Neonatology, 114: 223-225.

14. Gamaleldin R, Iskander I, Seoud I, Aboraya H, Aravkin A, Sampson PD and Wennberg RP (2011): Risk factors for neurotoxicity in newborns with sever neonatal hyperbilirubinemia. Pediatrics, 128(4):92531.

15. Akgül S, Korkmaz A, Yiğit S and Yurdakök M (2013): Neonatal hyperbilirubinemia due to ABO incompatibility: does blood group matter?. Turk J Pediatr., 55(5):506-9.

16. Umran M (2012): Neonatal Jaundice due to G6PD Deficiency. Pakistan Pediatric J., VIII (3):126-128.

17. Abd-Ellatif MA and Abd-Ellatif DA (2012): The use of intensive phototherapy in severe neonatal hyperbilirubinemia. J Egypt Soc Parasitol., 42(2):483-94.

18. De Carvalho $\mathrm{M}$, Mochdece $\mathrm{CC}$, Moura $\mathrm{CA}$ and Moreira M (2011): High-intensity phototherapy for the treatment of severe nonhaemolytic neonatal hyperbilirubinemia. Acta Pædiatrica, 100: 620-623.

19. Al-Hafidh J, Barquinero JF, Lindholm C, Moquet J, Perälä M, Roch-Lefèvre S, Scherthan H, Thierens H, Vral A and Vandersickel V (2013): Manual versus automated $\gamma-\mathrm{H} 2 \mathrm{AX}$ foci analysis across five European laboratories: can this assay be used for rapid biodosimetry in bilisphire radiation. Mutat Res., 756 (1-2):170-3.

20. Johnson $L$ and Bhutani VK (2011): The clinical syndrome of bilirubin-induced neurologic dysfunction. Semin Perinatol., 35(3):101-13.

21. Bradley A (2017): A decline in the frequency of neonatal exchange transfusions and its effect on exchange-related morbidity and mortality. Embryo project Encyclopedia. Pediatrics, 120(1):27-32. 